\title{
A Canonical Analysis on the Relationship between Banking Sector and Stock Market Development in Bangladesh
}

\author{
Suman Biswas ${ }^{1}$, Altaf Hossain ${ }^{1}$, Arnab Kumar Podder $^{1} \&$ Md. Nasif Hossain ${ }^{1}$ \\ ${ }^{1}$ Department of Statistics, Islamic University, Kushtia, Bangladesh \\ Correspondence: Suman Biswas, Department of Statistics, Islamic University, Kushtia - 7003, Bangladesh. Tel: \\ 88-017-4142-2147. E-mail: suman.iu09@gmail.com
}

Received: September 5, 2017

Accepted: November 30, 2017

Online Published: December 15, 2017

doi:10.5539/ijef.v10n1p167

URL: https://doi.org/10.5539/ijef.v10n1p167

\begin{abstract}
This study examines the structural dependency between the developments of banking sector and stock market of Bangladesh using canonical correlation analysis. The main objective is to check whether the developments of these two financial sectors independently behave in the economic activities of Bangladesh using monthly data from 2006 to 2015. The development of banking sector is measured by a set of four indicators or variables, private sector credit, total number of branches of scheduled banks, interest rate spread and non-performing loan. Similarly another set of indicators, stock market capitalization, number of listed companies, turnover ratio and stock price volatility are used to explain the development of stock market. The multivariate time series of the two set of indicators are ensured first to be the stationary one. Then the canonical correlation analysis between the two set of indicators show that private sector credit, total No. of branches of scheduled banks are the first set of variables contribute more to construct the first canonical variate of banking sector. Market capitalization and number of listed companies are the second set of variables contribute more to construct the first canonical variate of stock market development. Finally, the correlation between the first pair of canonical variates is 0.293 . Since the correlation is positive but not significant, banking and stock market developments do not significantly complement each other. Thus it is concluded that the developments of the two financial systems have been independently running during the period in financing economic activities of Bangladesh from 2006 to 2015.
\end{abstract}

Keywords: banking sector development, stock market development, canonical correlation analysis, Bangladesh

\section{Introduction}

The financial system of a country is the lifelines of its economy. It produces affluence that can be shared throughout society and benefit the poorest and most vulnerable people if the system works well. The importance of the financial sector on the country's real economy is very significant. The financial sector comprises financial institutions, financial markets, investment funds, insurance companies and real estate. There is an outline developed by The World Bank's Global Development Database. The outline identifies four sets of proxy variables describing a well - functioning financial system- financial depth, access, efficiency and stability. These four dimensions are then broken down into two major components in the financial sector and they are financial institutions (mainly banking) and financial markets (mainly stock market). It is remarkable that the banking sector has more contribution than the stock market to accelerating real economic activities, especially for developing countries like Bangladesh.

The banking sector is a part of a country's economy which is dedicated to the holding of financial assets for others and investing those financial assets as leverage to create more wealth. The sector is also devoted to the regulation of those activities by government financial agencies. A bank is generally assumed as an organization which provides the ultimate banking services such as accepting deposits and providing loans. Banks are a sub-division of the financial services providing industry. For modern trade and commerce a well-functioning and well-developed banking system is essential. Now-a-days, banks not only act as custodian of public money but also are indispensable as vital agent for maintenance of sound financial position of a country. Like most other countries, banking sector plays a pivotal role in real economic activities of Bangladesh. This sector can well be said as a barometer of its economic prosperity.

Again, the stock market is one of the most important version of financial market. For companies, it is also important to raise fund as "share capital" from individuals and institutions. This lets businesses to be publicly 
traded, or raise additional financial capital for balancing, modernizing, reconstruction or expansion (BMRE). This is done by selling shares of proprietorship of the company in a public market. Compared to other less liquid investments, stock market is a smart feature of investing in stocks. If a country's stock market is stable, there are healthy trading activity and strength in its economy. Rising prices of stocks and other securities are indicators or predictors to the level of economic growth. The performance of the stock market can also be seen as a measurement of public sentiment. Conversely, the general view of investors about the economy can also influence the stock market significantly.

In enhancing real economic activity, there is a debate concerning the relative roles of bank-based versus market-based financial systems. This debate has been going on for decades now (Levine, 2003). As bank-based financial system can bring longer-term investment in the real sector, Ndikumana (2005) claimed that it is better than a stock market based system. Specifically, there is a number of ways through which banks can boost domestic investment. Whereas investment in the market-based system is considered to be too sensitive to the stock market prices and may not be sustainable in the long run (Hoshi et al., 1990; Lee, 2001).

The current debate, which we are going to address in this study, is importantly about the complementarity versus the substitutability between the banking and stock market. Since both systems intermediate savings to investment, they can be seen as either substitutes or as complements (see Naceur et al., 2007). If the development of banking and stock market, the relationship between them is significant and positive one. In other words, the debate is about whether the development of banking sector and stock market approach independently or dependently towards investment. Some studies report that the development of banking sector and stock market approaches independently in financing economic activities. Some other show that both the systems depend each other's developments in economic activities. Examining a sample of Latin American and Asian countries, Garcia and Liu (1999) show that banking sector development has a positive impact on stock market development. Contrary to the above studies, Garcia (1986) finds a negative correlation between bank growth and stock market development. However, according to Yartey (2008), this relationship is non-monotonic. At the earlier stages of its development, banking sector functions as a complement to the stock market development. As the two systems develop, they begin to compete with each other in financing economic activities.

Concerning the matter, although there is a few number of works with different results or conclusions, but most of the existing works used only one indicator to explain one system. It is true that they used many indicators to explain the financial systems; they have done it individually, not jointly. But this is crucially expected to consider many variables, at least one from each dimension and then make their interaction effects. We should do it for both the systems, banking and stock market. That is, for banking sector, a set of indicators will be used to make a composite indicator by using a multivariate technique. By using the same multivariate method, another composite indicator will be formed for stock market. Finally making the correlation between the pair of composite indicators will be called canonical correlation. Finding this canonical correlation will be our general objective. Therefore, the objective of this study is to check the structural dependency between the development of banking sector and stock market of Bangladesh using canonical correlation analysis. That is, our objective is to checking whether banking sector and stock market are independently developed in the economic activity of Bangladesh by using monthly data from 2006 to 2015 .

The remaining part of the study is organized as follows. In section 2, existing important literature reviews are described briefly. Data and appropriate research methodologies are presented in section 3. Section 4 interprets and discuss about the results and analysis. Finally, conclusion is drawn on the basis of a rigorous summary in section 5 .

\section{Literature Review}

As banking sector and stock market development are vital issue of a country to represent its real economic activities, the relationship between these two sectors development are the matter of headache across the world. There is a debate concerning the relative roles of bank-based versus market-based financial systems. This debate has been going on for decades now (Levine, 2003). The promoters of the bank-based system argue that a bank-based financial system is better than a market-based system as it can bring longer-term investment in the real sector. Specifically, there is a number of ways through which banks can enhance domestic investment (see Ndikumane, 2005). By pooling financial savings, banks rise the amount of funds for investment purpose. It is also claimed that banks reduce liquidity risks, induce higher quality and quantity of investment and then the amount of investment is increased. Whereas investment in the market-based system is considered to be too sensitive to the stock market prices and may not be sustainable in the long run (Hoshi et al., 1990; Lee, 2001). It is also claimed that industrial policies of the government can be implemented more easily in a bank based system 
as it allows governments with more measures to interfere in the financial sector than the market-based system (Pollin, 1995). However, the moral hazard problem in the bank-based system is even worse. With the implicit government bailout, finance sometimes only does harm to the economy, making the system more vulnerable to financial crisis (Greenspan, 1999).

The current debate is importantly about the complementarity versus the substitutability between the banking and stock market. Since both systems intermediate savings to investment, they can be seen as either substitutes or as complements (see Naceur et al., 2007). In other words, the debate is about whether the banking sector and stock market behave independently or not in a country's economy. Some recent important studies have found that banks and stock markets are complementary rather than competitive systems (see Ndikumane, 2005). Currently, the important matter is that how the financial system is developed and efficient rather than whether a financial system is bank-based or stock market-based. Moreover, some other studies have found that the role of the stock market in economic growth is dependent on a country's stage of development. In the earlier stage, banks play a principal role in boosting economic growth. As a country touches higher levels of income, then stock markets tend to play an increasing role (see also Demirguc-Kunt \& Levine, 1999). This means that less-developed countries are anticipated to be mostly bank-based and more-developed countries are expected to have relatively larger and more liquid stock markets based. Unfortunately, there are a very few number of studies have tried to empirically examine the relationship between bank-based financial system and stock market development in financing economic activities of a country. As far we know, there is no study with Bangladesh during the considered period with monthly data. Although there are some studies, for example Garcia (1986), Boyd and Smith (1996), Demirguc-Kunt and Levine (1996), Garcia and Liu (1999), Naceur et al. (2007) and Yartey (2008), attempted to explore the relationship between the two systems.

Boyd and Smith (1996), for example, conclude that banks and stock markets may act as complements rather than substitutes. Demirguc-Kunt and Levine (1996) also founds that the degree of stock market development is positively related to that of bank development. In the case of MENA countries, Naceur et al. (2007) find that financial intermediaries and stock markets are complements rather than substitutes in the growth process. Garcia and Liu (1999) also showed that financial intermediary development has a positive impact on stock market development in a sample of Latin American and Asian countries. Contrary to the above studies, Garcia (1986) argues that there may have a negative correlation between bank growth and stock market development. However, according to Yartey (2008), the relationship between the two systems is non-monotonic. At the early stages of its development banking sector development serves as a complement to the stock market development in financing investment. However, as the two systems develop, they begin to compete with each other as vehicles for financing investment.

The works could be done by multivariate statistical technique, canonical correlation. Because, there are two sets of variables or indicators to explain the development two systems; one for baking system and another for stock market. For far more details, see (Hair et al., 1998; Andrews et al., 1998). Most of the existing studies used only single or two indicators from each sector to explain the relationship between banking sector and stock market development and they find the simple relationship between them. They did not use canonical correlation analysis between the two set of variables or indicators of banking and stock market. Since there are many indicators, importantly, private sector credit, stock market capitalization, number of listed companies, interest rate spread, turnover ratio and non-performing loan categorized to measure the banking sector and stock market, so it is difficult to measure the proper relationship between these sector in a simple way. This is another research gap in the existing studies. To avoid these difficulties in this study the canonical correlation analysis will be used as described in introduction section.

\section{Data and Methodology}

\subsection{Data and Variable Description}

The monthly data set is extracted from the Monthly Economic Trends which is published by Bangladesh Bank for the time period from 2006 to 2015. Bangladesh financial sector are broken down into two components called financial institution and financial market. In addition, these two components are categorized under four dimensions- financial depth, access, efficiency, and stability. Data are collected on Domestic Credit to the Private sector by Bank (DCPB), No. of Branches of Scheduled Banks (NBSB), Interest rate spread of Scheduled Banks (Lending rate- deposit rate, \%) (IRS) and Bank non-performing loan to total gross loans (NPLs) so that they would represent each dimensions of the financial institution (especially banking sector).

Moreover, data are collected on total Market Capitalization (MC), Number of Listed Companies (NLC), Stock Market Turnover or value traded/capitalization (TOR) and Stock price volatility (PV) which represent different 
dimensions of financial market (especially stock market).

\subsection{Methodology}

\subsubsection{Unit Root Test}

Unit root tests are tests for checking the stationarity of a time series. If a shift in time doesn't cause a change in the shape of the distribution of the series is referred to as a stationary; contrary to the series is called non stationary. Unit roots are one cause for non-stationarity. Non-stationary data can then be converted to stationary by differencing $k$ times, it is said to be integrated of order $k$, denoted $\mathrm{I}(\mathrm{k})$; therefore a series is stationary at level, it is donated by I(0). Augmented Dickey-Fuller test (ADF), introduced by Dickey and Fuller $(1979 ; 1981)$, is used to check the stationarity of the data. To conserve space, unit root tests' details are not provided and interested readers are reoffered to original papers by the authors.

\subsubsection{Canonical Correlation Analysis}

Canonical correlation analysis is used to study the relationship between the linear combination of one set of variables and a linear combination of another set of variables. It is the multivariate extension of correlation analysis which is first introduced by H. Hotelling (1936). Generally, this analysis is used for the purposes of data reduction and evaluating the independency of two sets of variables (Raykov \& Marcoulides, 2008). The maximization aspect of the canonical correlation analysis represents an attempt to concentrate a high dimensional relationship between two sets of variables into a few pairs of canonical variates. It is also effectively useful in measuring the relationship between our social activities, which is the influence of one to another.

Canonical correlation reflects the percent of variance in the dependent canonical variables (consisting of weighted linear combinations i.e., variates) explained by the independent canonical variables and is used when exploring relationships between the independent and the dependent set of variables.

Suppose a data set $X$, partition the collection of the variables into two sets: $X_{(p \times 1)}^{(1)}$ and $X_{(q \times 1)}^{(2)}$ (assume that $p \leq q)$

Introducing the linear combinations, $U=a^{\prime} X^{(1)}, \quad V=b^{\prime} X^{(2)}$

For these, $\operatorname{Var}(U)=a^{\prime} \operatorname{var}\left(X^{(1)}\right) a, \operatorname{Var}(V)=b^{\prime} \operatorname{var}\left(X^{(2)}\right) b$ and $\operatorname{Cov}(U, V)=a^{\prime} \operatorname{cov}\left(X^{(1)}, X^{(2)}\right) b$

Where $\mathrm{U}$ and $\mathrm{V}$ are called canonical variables (i.e. variates) and $\mathrm{a}$ ' and $\mathrm{b}$ ' represents the weight for that variables respectively. The correlation between $\mathrm{U}$ and $\mathrm{V}$ variates is referred to as the canonical correlation which is defined as:

$$
\operatorname{Corr}(U, V)=\frac{\operatorname{Cov}(U, V)}{\sqrt{\operatorname{Var}(U)} \sqrt{\operatorname{Var}(V)}}
$$

Weights (a' and b') are selected so as to maximize the canonical correlation $\operatorname{Corr}(U, V)$ between the variate representing the dependent variables and the variate representing the independent variables.

\section{Result and Discussion}

As the values of all variables are in different unit, they are expressed in standardized values to make them unit free. Abbreviated names of the original variables are then changed to ZDCPB, ZNBSB, ZIRS, ZNPL, ZMC, ZPV, ZTOR and ZNLC respectively. How the variables are related each other can be shown through the matrix plot. Figure 1 represents the matrix plot of the variables from which we can see the relationship between variables and how they are distributed. 


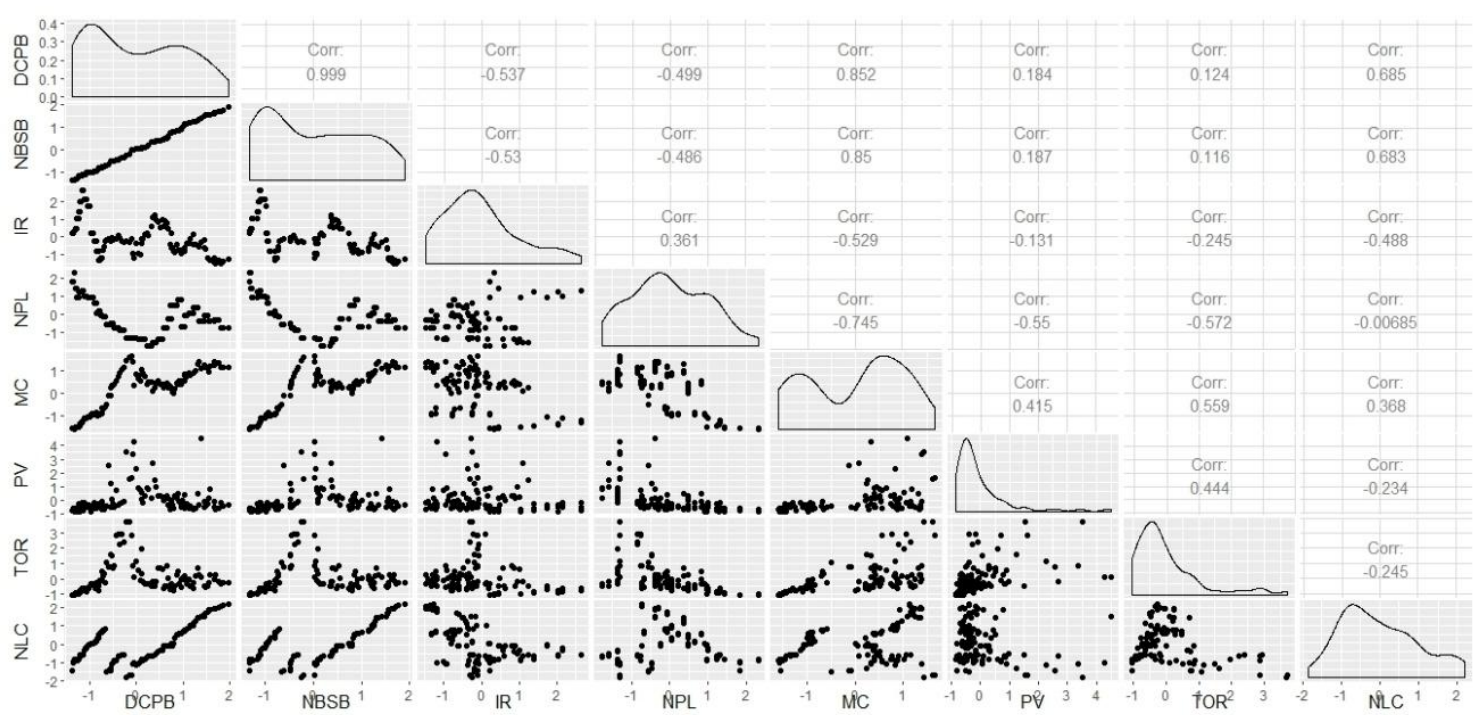

Figure 1. Matrix plot of the standardized data

The analysis considers the multivariate time series data. Thus it is important to examine whether the variables are stationary. The Augmented Dickey-Fuller (ADF) test is used to test the stationarity of the variables. Table 1 shows the Augmented Dickey-Fuller (ADF) test statistic and corresponding P-values. From Table 1 it is seen that all the variables used in this study are nonstaionary. Moreover it is important to make all the variables stationary before conducting further analysis. To make all the variables stationary, first differencing is used for each series or variable. After taking first differencing in all variables they are named to DZDCPB, DZNBSB, DZIRS, DZNPL, DZMC, DZPV, DZTOR and DZNLC and the ADF test is used to check the stationarity.

Table 1. Unit Root (ADF) test results of standardized data

\begin{tabular}{lll}
\hline Variables & Test Statistic & P value \\
\hline ZDCPB & -1.3408 & 0.8503 \\
ZNBSB & -2.0314 & 0.5636 \\
ZIR & -3.0003 & 0.1611 \\
ZNPL & -1.9358 & 0.6033 \\
ZMC & -1.712 & 0.6962 \\
ZPV & -3.1192 & 0.1117 \\
ZTOR & -1.9895 & 0.5809 \\
ZNLC & -1.2614 & 0.8833 \\
\hline
\end{tabular}

Note. $* * * * * * *$ indicates stationary at $1 \% / 5 \% / 10 \%$ respectively.

The ADF test results of the first differenced data are given in Table 2. The result from Table 2 ensures that all the variables become stationary after first differencing.

Table 2. Unit Root (ADF) test results of differenced data

\begin{tabular}{lll}
\hline Variables & Test Statistics & P value \\
\hline ZDCPB & -4.093 & 0.01 \\
ZNBSB & -5.7179 & 0.01 \\
ZIR & -3.8874 & 0.01 \\
ZNPL & -5.4812 & 0.01 \\
ZMC & -4.8449 & 0.01 \\
ZPV & -6.4744 & 0.01 \\
ZTOR & -5.3295 & 0.01 \\
ZNLC & -5.2766 & 0.01 \\
\hline
\end{tabular}

Note. $* * * / * * / *$ indicates stationary at $1 \% / 5 \% / 10 \%$ respectively. 
After making all the variables stationary we can again see the relationship between variables and how the variables are distributed. From Figure 2 it is seen that all variables are almost normally distributed which are one of the most important assumptions before checking the structural relationship. Therefore we will use the first differenced data for the remaining analysis.

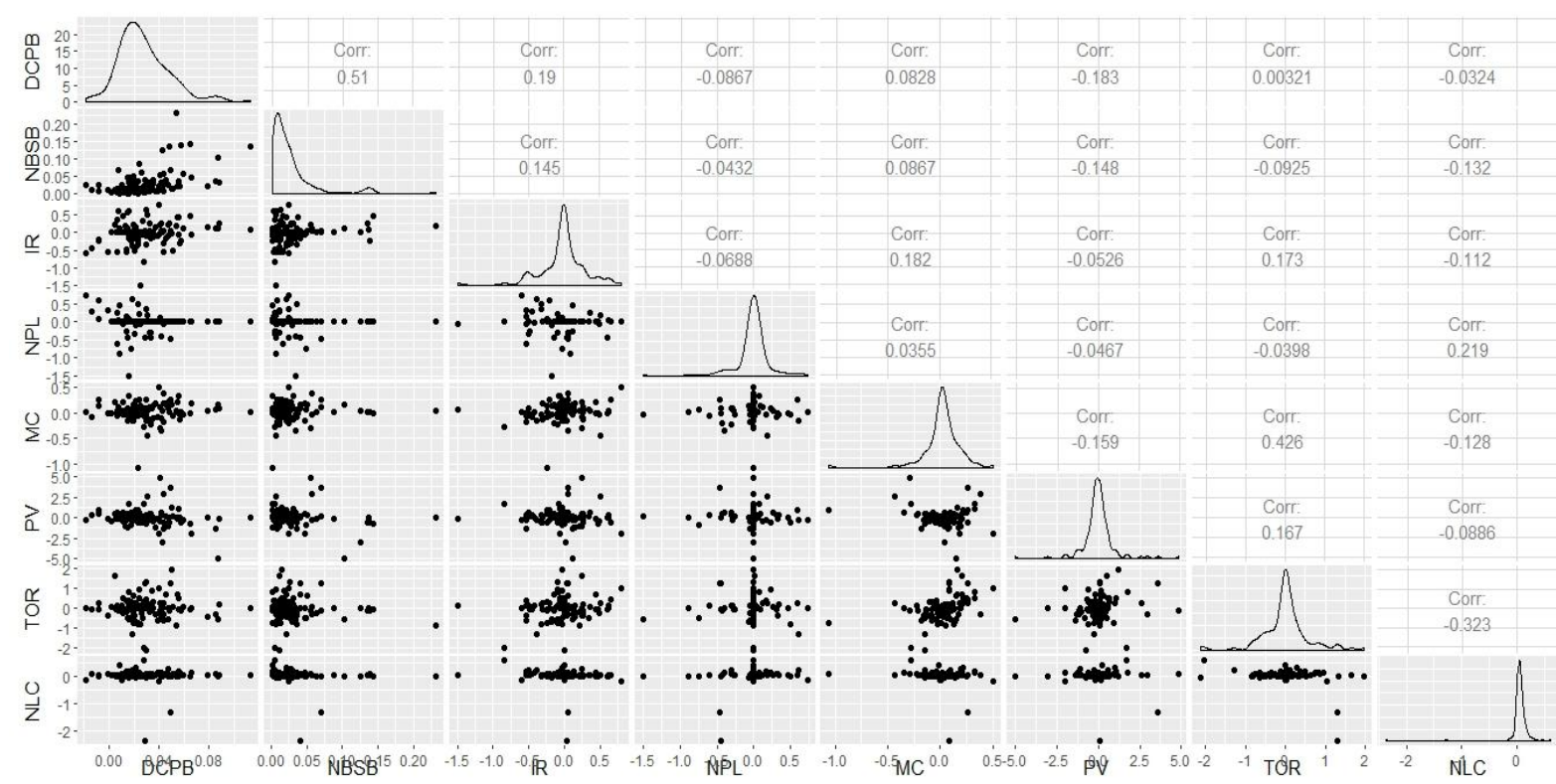

Figure 2. Matrix plot of the $1^{\text {st }}$ differenced data

In this study we want to see the structural relationship between banking sector and stock market development. Thus we divided all the variables into two sets. One of them is named Banking sector development which consist the variables DZDCPB, DZNBSB, DZIRS and DZNPL. Another one is named stock market development consisting DZMC, DZPV, DZTOR and DZNLC variables. Next we will look at the correlations within and between these two sets of variables. Table 3 and Table 4 represent the correlation within two sets of variables respectively and Table 5 represents the correlation between two sets of variables.

Table 3. Correlations within $1^{\text {st }}$ set of variables

\begin{tabular}{lcccc}
\hline Variables & DZDCPB & DZDCPB & DZDCPB & DZDCPB \\
\hline DZDCPB & 1 & & & \\
DZNBSB & 0.5103 & 1 & & \\
DZIR & 0.1904 & 0.1452 & 1 & \\
DZNPL & -0.0867 & 0.0432 & -0.0688 & 1 \\
\hline
\end{tabular}

Table 4. Correlations within 2nd set of variables

\begin{tabular}{lllll}
\hline Variables & DZMC & DZPV & DZTOR & DZNLC \\
\hline DZMC & 1 & & & \\
DZPV & -0.1588 & 1 & & \\
DZTOR & 0.4264 & 0.1671 & 1 & \\
DZNLC & -0.1276 & -0.0886 & -0.3227 & 1 \\
\hline
\end{tabular}

In Table 5 the correlation between two set of variables is shown from which interpreting the relationships are ordinarily hopeless. Moreover, it is often linear combinations of variables that are interesting and useful for comparative purposes. That is, we need the canonical correlation analysis to summarize the association between these two set of variables. 
Table 5. Correlations between $1^{\text {st }}$ and $2^{\text {nd }}$ set of variables

\begin{tabular}{lllllllll}
\hline & DZDCPB & DZNBSB & DZIR & DZNPL & DZMC & DZPV & DZTOR & DZNLC \\
\hline DZDCPB & 1 & & & & & & & \\
DZNBSB & 0.5103 & 1 & & & & & & \\
DZIR & 0.1904 & 0.1452 & 1 & & & & & \\
DZNPL & -0.0867 & -0.0432 & -0.0688 & 1 & & & \\
DZMC & 0.0828 & 0.0867 & 0.1824 & 0.0355 & 1 & & \\
DZPV & -0.1827 & -0.1482 & -0.0526 & -0.0467 & -0.1588 & 1 & \\
DZTOR & 0.0032 & -0.0925 & 0.1727 & -0.0398 & 0.4264 & 0.1671 & 1 & 1 \\
DZNLC & -0.0324 & -0.1315 & -0.1121 & 0.2193 & -0.1276 & -0.0886 & -0.3227 & 1 \\
\hline
\end{tabular}

After conducting canonical correlation analysis it is found that canonical correlations between four canonical variate pairs are $0.293,0.233,0.207$ and 0.098 respectively. Again the canonical variate coefficients of banking sector and stock market development are given in Table 6 and Table 7 resepectively.

Table 6. Canonical variate coefficients of $1^{\text {st }}$ set of variables

\begin{tabular}{lcccc}
\hline & $\widehat{\boldsymbol{a}}_{\mathbf{1}}$ & $\widehat{\boldsymbol{a}}_{\mathbf{2}}$ & $\widehat{\boldsymbol{a}}_{\mathbf{3}}$ & $\widehat{\boldsymbol{a}}_{\mathbf{4}}$ \\
\hline DZDCPB & 9.7172 & 28.2342 & 12.1580 & 45.4889 \\
DZNBSB & -23.8699 & -4.3956 & 15.6106 & -16.5820 \\
DZIRS & -0.5868 & 2.2493 & -2.0208 & -1.2719 \\
DZNPL & 2.2927 & 1.7448 & 2.0549 & -1.7940 \\
\hline
\end{tabular}

Table 7. Canonical variate coefficients of 2 nd set of variables

\begin{tabular}{lcccc}
\hline & $\widehat{\boldsymbol{b}}_{\mathbf{1}}$ & $\widehat{\boldsymbol{b}}_{\mathbf{2}}$ & $\widehat{\boldsymbol{b}}_{\mathbf{3}}$ & $\widehat{\boldsymbol{b}}_{\mathbf{4}}$ \\
\hline DZMC & -1.6572 & 2.9353 & 1.0573 & -5.7447 \\
DZPV & 0.1895 & -0.5712 & -0.3831 & -0.7247 \\
DZTOR & 0.8752 & 0.8442 & -1.4183 & 1.03999 \\
DZNLC & 3.6850 & 0.9316 & 0.8588 & -0.4189 \\
\hline
\end{tabular}

Table 8 represent the test of $H_{01}: \rho_{1} \neq 0, \rho_{2}=\rho_{3}=\rho_{4}=0, H_{02}: \rho_{1} \neq 0, \rho_{2} \neq 0, \rho_{3}=\rho_{4}=0, H_{03}: \rho_{1} \neq 0, \rho_{2} \neq$ $0, \rho_{3} \neq 0, \rho_{4}=0$ and $H_{04}: \rho_{1} \neq 0, \rho_{2} \neq 0, \rho_{3} \neq 0, \rho_{4} \neq 0$. The results show that the null hypotheses are not significant at $5 \%$ and $10 \%$ level of significance.

Table 8. Test statistics

\begin{tabular}{lccccc}
\hline Canonical Variate Pair & WilksL & F- Statistic & df1 & df2 & P-value \\
\hline First & 0.8191901 & 1.432459 & 16 & 339.7482 & 0.1239351 \\
Second & 0.8962977 & 1.394331 & 9 & 272.7292 & 0.1903874 \\
Third & 0.9479140 & 1.531523 & 4 & 226.0000 & 0.1938965 \\
Fourth & 0.9904149 & 1.103275 & 1 & 114.0000 & 0.2957701 \\
\hline
\end{tabular}

Specially, in this study we will explain about first canonical variate pair as they represent the highest correlation. From Table 6 and Table 7 the first canonical variate pair with canonical correlation 0.293 can be written as

$$
\begin{gathered}
\widehat{U}_{1}=9.7172 \text { DZDCPB }-23.8699 \text { DZNBSB }-0.5868 \text { DZIRS }+2.2927 \text { DZNPL } \\
\widehat{V}_{1}=-1.6572 \text { DMC }+0.1895 \text { DZPV + 0.8752 DZTOR + 3.6850 DZNLC }
\end{gathered}
$$

According to the coefficients, $\widehat{U}_{1}$ is primarily a DZDCPB and DZNBSB variable, while $\widehat{V}_{1}$ represents DZMC and DZNLC. To provide interpretation for $\widehat{U}_{1}$ and $\widehat{V}_{1}$, the correlation between $\widehat{U}_{1}$ and its component variables and between $\widehat{V}_{1}$ and its component variables are computed. The Table 8 shows the sample correlation between variables in banking sector development and the first canonical variate also with second canonical variate. Similarly the correlation between stock market development and first and second canonical variates shows in Table 8 .

From the results of Table 9 it is seen that all four banking sector development variables have the highest correlations with the first canonical variate $\widehat{U}_{1}$. From this standpoint, $\widehat{U}_{1}$ might be interpreted as banking sector development "index". 
Table 9. Correlations between original variables and canonical variables

\begin{tabular}{lccccc}
\hline $\mathbf{1}^{\text {st }}$ set of Variables & $\widehat{\boldsymbol{U}}_{\mathbf{1}}$ & $\widehat{\boldsymbol{V}}_{\mathbf{1}}$ & $\mathbf{2}^{\text {nd }}$ set of Variables & $\widehat{\boldsymbol{U}}_{\mathbf{1}}$ & $\widehat{\boldsymbol{V}}_{\mathbf{1}}$ \\
\hline DZDCPB & -0.3059 & -0.08971174 & DZMC & -0.06765561 & -0.23066472 \\
DZNBSB & -0.7819 & -0.22933548 & DZPV & 0.06864062 & 0.23402302 \\
DZIR & -0.3026 & -0.08862615 & DZTOR & 0.02371770 & 0.08086301 \\
DZNPL & 0.6115 & 0.17936860 & DZNLC & 0.25074314 & 0.85488254 \\
\hline
\end{tabular}

Similarly, all four stock market development variables have highest correlations with the first canonical variate $\widehat{V}_{1}$. Thus canonical variate $\widehat{V}_{1}$ might be regarded as stock market development index. The canonical correlation between two indices $\widehat{U}_{1}$ and $\widehat{V}_{1}$ is 0.293 which is not significant at $5 \%$ and $10 \%$ level of significance. That is, it can be said that the banking sector and stock market development is not highly correlated and their correlation is not significant at 5\% or 10\% level of significance in the case of Bangladesh during the period of 2006-2015. In other words, there didn't appear to be some overlap between banking sector and stock market development of Bangladesh in the period of 2006-2015.

\section{Summary and Conclusion}

It is crucial to know whether the developments of banking and stock market complement or substitute each other in financing economic activities of Bangladesh. Since both banks and stock markets accumulate funds or savings for investment, they can be seen as either substitutes or as a complements (see Naceur et al., 2007). Some recent studies, for example Boyd and Smith (1996) and Ndikumane (2005) found that banks and stock markets are complementary rather than competitive systems; that is, both systems develop independently in funding economic activities. Some other studies showed that both systems substitute each other in their development. For example, Demirguc-Kunt and Levine (1996) and Garcia and Liu (1999) showed that the degree of stock market development is positively related to that of bank development. Similar results were obtained by Naceur et al. (2007) in the case of MENA countries. In addition, the role of the stock market in economic growth is dependent on a country's stage of development. Unfortunately, very few studies have attempted to empirically examine the relationship between bank-based financial system and stock market development. Amongst other, Garcia (1986), Boyd and Smith (1996), Demirguc-Kunt and Levine (1996), Garcia and Liu (1999), Naceur et al. (2007) and Yartey (2008), addressed the issue of linkage between the two systems, banking and stock markets.

However, using one indicator or variable from each system of banking and stock market, most of the existing studies found the pairwise relationship between the developments of these two system in funding economic activities. But this is not enough for a single indicator or variable to explain the development of a system. There are many more indicators needed to explain the development of a system, banking or stock market. In addition the indicators of the development of a system have important interaction effects needed to be accounted for the purpose. This is not possible to find the relationship well by using the frequently used simple methods. Here the multivariate method, canonical correlation is appropriate to find the relationship between the developments of banking and stock market.

For the purpose, there are many indicators, at least, private sector credit, total No. of Branches of Scheduled Banks, interest rate spread and non-performing loan from each dimension to explain the development of the banking system. Similarly, stock market capitalization, number of listed companies, turnover ratio and stock price volatility are taken from each dimension to explain the development of stock market. Then using a multivariate method, two composite indicators are made to be accounted for the interaction effects of many indicators. One composite indicator is for assessing the development of banking sector and another for the stock market. Then making correlation between this pair of composite indicators is called canonical correlation between the two sets (banking and stock market) of indicators. The process of the canonical method is broadly discussed in the methodology. So our general objective is to examine the relationship between the developments of banking and stock market by using an appropriate multivariate statistical method, canonical correlation analysis. The study covers the period of 2006 to 2015 and the data on the relevant variables are collected on the monthly basis.

As the values of all variables are in different unit, they are expressed in standardized values to make them unit free. The analysis considers the multivariate time series data. Thus it is important to examine whether the variables are stationary. The Augmented Dickey-Fuller (ADF) test is used to test the stationarity of the variables. After taking first differencing in all variables the variables become stationary. The matrix plot of the differenced variables shows the relationship between variables and also shows that the variables are almost normally distributed. 
Since, we want to see the structural relationship between the development of the two systems, all the indicators or variables are divided into two sets named, banking and stock market. From the correlation matrix of within and between two sets of variables it is very ambiguity to make the interpretation of the relationship between two set of variables. Thus canonical correlation analysis has been used to see the structural relationship between two set of variables. From the canonical results it is seen that the first set of variables make the banking sector development index and the second set variables make the stock market development index. Furthermore, from the first pair of canonical variate pair it is seen that DZDCPB and DZNBSB of first set of variables contribute more to construct first canonical variate of banking sector and DZMC and DZNLC of second set of variables contribute more to construct first canonical variate of stock market development. The correlation between first pair of canonical variate is 0.293 which is relatively small and is not significant at $5 \%$ or $10 \%$ level of significance. Thus it is concluded that the developments of banking sector and stock market are not complement each other; rather they are independently developed in Bangladesh during the period of 2006-2015.

\section{References}

Boyd, J., \& Smith, B. D. (1996). The Coevolution of the Real and Financial Sectors in the Growth Process. World Bank Economic Review, 10, 371-396. https://doi.org/10.1093/wber/10.2.371

Crum, M. R., Lund, D. B., \& Van Auken, H. E. (1987). A canonical correlation analysis of carrier financial strategy: The case of airline deregulation. Transportation Research Part A: General, 21(3), 179-190. https://doi.org/10.1016/0191-2607(87)90012-4

Demirguc-Kunt, A., \& Levine, R. (1996). Stock Markets, Corporate Finance and Economic Growth: An Overview. World Bank Economic Review, 10(May), 223-239. https://doi.org/10.1093/wber/10.2.223

Demirgüç-Kunt, A., \& Levine, R. B. (1999). Bank-based and Market-Based Financial Systems: Cross-Country Comparisons. The World Bank, Policy Research Working Paper 2143.

Dickey, D. A., \& Fuller, W. A. (1979). Distribution of the Estimators for Autoregressive Time Series with a Unit Root. Journal of American Statistical Association, 74, 427-81.

Dickey, D., \& Fuller, W. A. (1981). Likelihood ratio statistics for autoregressive time series with a Unit Root. Econometrica, 49, 1057-72. https://doi.org/10.2307/1912517

Garcia, F. V., \& Liu, L. (1999). Macroeconomic Determinants of Stock Market Development. Journal of Applied Economics, 2(1), 29-59.

Garcia, V. F. (1986). Critical Enquiry into Argentine Economic History 1946-1970. Garland Publishing Co., New York.

Hester, D. D., \& Zoellner, J. F. (1966). The relation between bank portfolios and earnings: An econometric analysis. Review of Economics and Statistics, 48, 372-386. https://doi.org/10.2307/1924615

Hoshi, T., Kashyap, A., \& Scharfstein, D. (1990). The Role of Banks in Reducing the Costs of Financial Distress in Japan. Journal of Financial Economics, 27, 67-88. https://doi.org/10.1016/0304-405X(90)90021-Q

Hotelling, H. (1936). The relationship between two of variables. Biometrica, 28(3-4), 321-377. https://doi.org/10.1093/biomet/28.3-4.321

Kongkook, L. (2001). Note on Study of the Changes of Financial System. Ref. 00.12-Department of Economics, University of Massachusetts.

Levine, R. (2003). Stock Markets Liquidity and Economic Growth: Theory and Evidence. In L. Paganetto, \& E. S. Phelps (Eds.), Finance, Research, Education and Growth. Palgrave Macmillan, New York. https://doi.org/10.1057/9781403920232_1

Naceur, B. S., Ghazouani, S., \& Omran, M. (2007). The Determinants of Stock Market Development in the Middle-Eastern and Northern African Region. Managerial Finance, 33, 477-489. https://doi.org/10.1108/03074350710753753

Ndikumana, L. (2005). Financial Development, Financial Structure, and Domestic Investment: International Evidence. Journal of International Money and Finance, 24, 651-673. https://doi.org/10.1016/j.jimonfin.2005.03.006

Stowe, J. D., Watson, C. J., \& Robertson, T. D. (1980). Relationships between the two sides of the balance sheet: A canonical correlation analysis. The Journal of Finance, 35(4), 973-980. https://doi.org/10.1111/j.1540-6261.1980.tb03514.x 
Yartey, C. A. (2008). The Determinants of Stock Market Development in Emerging Economies: Is South Africa Different? IMF Working Paper No. WP/08/32.

\section{Copyrights}

Copyright for this article is retained by the author(s), with first publication rights granted to the journal.

This is an open-access article distributed under the terms and conditions of the Creative Commons Attribution license (http://creativecommons.org/licenses/by/4.0/). 